\title{
NEWS ABOUT PESTICIDES
}

RIRDS which feed on fish or other freshwater food, such as herons and bitterns, showed the highest average residues of organo-chlorine compounds among those analysed, says the fifth report of the Joint Committee of the British Trust for Ornithology and the Royal Society for the Proteotion of Birds. The second highest concentrations were in diurnal and nocturnal birds of prey, confirming the view that it is the birds at the end of the food chain that suffier most. Of the 236 bodies from 84 species examined, only 4 per cent. were completely free of organo-chlorine residues, and none of the 145 eggs of 34 species was free. Analysis of some inseots and other invertebrates yielded a dragonfly from Hampshire with residues of no fewer than four organo-chlorine compounds, and beetles, woodlice, caterpillars, worms and slugs all showed contamination.

The Committee, while welcoming the voluntary ban on certain uses of aldrin, dieldrin and heptachlor, feels that there is still the danger of a build-up of the persistenit BHC and DDT. It also suggests that the voluntary nature of the restrictions is unsatisfactory, and refers to the reports of stock-piling of dieldrin sheep dips, which, it says, should be compulsorily surrendered - and not dumped in rivers, or the sea, or used on land.

In a paper on Pesticides and Birds in Bird Study, Dr Norman Moore suggests that the special problems posed by the persistent insecticides such as the organo-chlorine chemicals, should not divert attention from other pestlicides, and particularly herbicides. Although most of them are only slightly toxic to birds, they may have a considerable effect on bird populations by affecting their food supply and, as they are now widely used in this country, they must have an enormous effect on flowering plants and so indirectly on insects. Dr Moore surggests that this raises a difficult problem for conservationists. It is reasonable to object to the direct poisoning of birds by insecticides, but much more difficult to object to herbioides which, by controlling weeds efficiently, reduce the amount of food available to birds.

Three American scientists from Pennsylvania State University have shown that plants can absorb insecticides from the soil through their roots, and pass them on to grazing cattle. Dairymen in Pennsylvania had had to throw away milk because it contained amounts of DDT or dieldrin above limits prescribeld by inter-state law. The scientists' report also showed that even though a crop had not been sprayed in the year of harvest, pesticide residues remaining in the soil from previous years could be absorbed by a new unsprayed crop.

In the past twenty years some 200 species of pests have developed immunity to the pesticides devised to kill them, it was reported at a meeting of an FAO working party on pest resistance. It was stated caltegorically that the assumption that powerful pesticides virtually promised permanent control of most agricultural pest's is no longer valid.

\section{Aleutian Bird Refuge Saved from Sheep}

A request from a Texas livestock firm to graze 9,000 sheep on two islands, Kanaga and Tanaga, in the Aleutian Islands National Wildlife Refuge, which are a breeding ground for the bald eagle, was turned down by the Department of the Interior on the ground that it would lead to considerable loss of plant oover and soil erosion. In addition to at least 60 pairs of bald eagles breeding on the islands, the Refuge is also a nesting and wintering ground for the emperor goose and a feeding ground for the rare Aleutian goose, an endangered species. 